\title{
LA SELECCIÓN NATURAL, UNA IDEA EVOLUTIVAMENTE BIEN ADAPTADA
}

\author{
Matías Daniel Pasqualini \\ Universidad Nacional de Rosario \\ (Argentina) \\ matiaspasqualini@gmail.com
}

\begin{abstract}
Resumen: En el siglo XIX, Darwin propuso un mecanismo para explicar la evolución de las especies biológicas. La teoría de la evolución por selección natural se reveló pronto como una idea revolucionaria. Sus contemporáneos percibieron el enorme potencial de esta idea para desplazar otras arraigadas en el campo científico cultural. Así como una especie biológica evolutivamente madura es capaz de desplazar otras formas vitales menos adaptadas e invadir el campo de la naturaleza, la misma idea de la selección natural se mostró como una idea evolutivamente potente, capaz de invadir gran parte del campo científico cultural. La teoría de la evolución por selección natural, originalmente concebida para explicar la evolución de las formas vitales, se muestra fecunda también al participar en actuales explicaciones del fenómeno mental y cultural. En esta presentación pretendemos mostrar sumariamente los elementos constitutivos de la teoría y su aplicación originaria a la evolución de las especies. Luego, buscaremos mostrar algunas aplicaciones alternativas de la teoría, para poner en evidencia su potencial explicativo. Por último, intentaremos hallar la razón de la mencionada potencia explicativa de esta teoría.
\end{abstract}

Palabras clave: Evolución, Selección natural, Naturalismo, Teleologismo

\begin{abstract}
In the 19th century, Darwin proposed a mechanism to explain the evolution of biological species. The theory of evolution by natural selection soon revealed itself as a revolutionary idea. Darwin's contemporaries perceived the enormous potential of this idea to displace others in the cultural scientific field. Just as an evolutionarily mature biological species is able to displace other less adapted life forms and invade the field of nature, the very idea of natural selection was shown to be an evolutionarily powerful idea capable of invading much of the cultural scientific field. The theory of evolution by natural selection, originally conceived to explain the evolution of vital forms, is also fruitful by participating in current explanations of the mental and cultural phenomenon. In this presentation we intend to briefly show the constitutive elements of the theory and its original application to the evolution of species. We will then try to show some alternative applications of the theory, in order to display its explanatory potential. Finally, we will try to find the reason for the aforementioned explanatory power of this theory.
\end{abstract}

Keywords: Evolution, Natural selection, Naturalism, Teleologism 


\section{1.- La evolución por selección natural. Elementos constitutivos de}

\section{la teoría}

Debe atribuirse a Lamarck el recurso a la noción de evolución para dar cuenta de la variedad de especies en el campo de la biología. Si bien autores anteriores daban cuenta de la posibilidad de transformación de las especies a partir de un número de especies originarias, la idea de que el cambio obedece a una suerte de necesidad de evolución progresiva en el grado de complejidad de las formas vitales pertenece al mencionado Lamarck (Rostand 1994, p. 79). Sin embargo, el papel atribuido por este autor a las circunstancias del medio como factor determinante de la evolución de las especies no fue incorporado al acervo del saber biológico. En efecto, este autor postulaba -sin suficiente fundamento- en su "segunda ley", que los caracteres desarrollados por el uso y los debilitados por el desuso, son comunicados por herencia a la descendencia (Lamarck 1986, p. 175). En términos contemporáneos, el error de Lamarck consistía en suponer que la variación en el fenotipo equivalía a una variación en el genotipo.

Habrá que esperar a Darwin para disponer de una explicación razonable del mecanismo evolutivo. El pensamiento del biólogo se vio oportunamente estimulado por una idea del economista Malthus, según la cual el crecimiento de una población entra periódicamente en una fase crítica debido a la escasez de recursos naturales (Rostand 1994, p. 123). Suponiendo ciertos factores que hacen que en una determinada generación de individuos de una especie exista cierta variabilidad de caracteres (entre los que Darwin cuenta el factor supuesto por Lamarck), y suponiendo la disposición limitada de recursos, ha de darse entre los individuos de la especie una competencia por los recursos, que forzará a que sobrevivan los individuos mejor adaptados al medio, quienes luego comunicarán a la segunda generación aquellos caracteres que resultaron exitosos. Darwin tiene ahora un mecanismo para explicar la acumulación de caracteres que facilitan la adaptación de los individuos al medio y eventualmente hacen posible la evolución de toda la especie: "A esta conservación de las diferencias y variaciones individualmente favorables y la destrucción de las que son perjudiciales la he llamado yo selección natural o supervivencia de los más adecuados" (Darwin 1921, p. 77).

Debe notarse que el mecanismo de la selección natural tal como fue presentado por Darwin explica cómo se conservan y acumulan caracteres que van progresivamente modificando la especie, pero no explica cómo surgen las variaciones en los individuos. 
Darwin tenía que suponer cierta variabilidad originaria y espontánea, o apelar al mecanismo que Lamarck explicitó. No obstante, a pesar de este costado todavía no satisfactorio de la teoría, la selección natural tiene desde el primer momento la virtud de no forzar una confusión entre fenotipo y genotipo, como ocurría en Lamarck. El mecanismo de la selección natural puede funcionar contando únicamente con variación genotípica, aunque no existiera variación fenotípica alguna (a lo Lamarck). Dependerán de un futuro aporte de Weismann una clara distinción entre variaciones innatas (genotípicas) y adquiridas (fenotípicas o somáticas) y una declaración de la imposibilidad de una influencia de las segundas sobre las primeras. Weismann habría de expulsar todo residuo lamarckiano de la teoría de Darwin (Rostand 1994, p. 152). ${ }^{1}$

La última pieza que necesitamos para contar con un cuadro relativamente completo de la teoría de la evolución por selección natural es precisamente una explicación de los mecanismos de la variabilidad genética. Antes de Mendel, la imagen que se tenía del conjunto de caracteres que un individuo podía heredar a otro, era más bien la de un todo indiferenciado. Su trabajo torna posible la identificación de caracteres hereditarios particulares, y la cuantificación precisa de la proporción en que determinado carácter será heredado por la descendencia (Rostand 1994, p. 174). Tenemos ahora una teoría que explica por qué a pesar del repetido cruzamiento entre individuos dentro de una especie, la variabilidad genética no se diluye, sino que se conserva: caracteres recesivos que quedan ocultos en una segunda generación, pueden volver a aparecer en una tercera. Posteriormente, Morgan logrará localizar en los cromosomas estas unidades mendelianas de la herencia (Rostand 1994, p. 184).

Otro factor de variabilidad genética había sido introducido por De Vries: son posibles súbitas mutaciones del patrimonio genético en su transmisión de una generación a otra. Algunas de estas mutaciones resultarán evolutivamente bien adaptadas al medio y se incorporarán eventualmente a la especie (Rostand 1994, p. 178). La posibilidad de la mutación genética (entendida en términos actuales como un error de copia del ADN) es

\footnotetext{
1Un dato curioso sobre las ideas de Weismann es que este autor supone no sólo una selección natural entre individuos sino también una selección natural entre genes (Rostand 1994, p. 155). Una idea análoga puede encontrarse en Dawkins, quien considera que la unidad de selección natural es el gen. Este autor ejemplifica esta selección natural entre genes con el caso de un gen parásito que "engaña" a los otros genes para reproducirse en mayor proporción, afectando la meiosis, incluso con un posible efecto letal para el individuo. Es el caso del gen $t$ del ratón (Dawkins 1993, p. 311).
} 
un dato particularmente importante para contar con una teoría de la evolución por selección natural consistente. Si sólo contáramos con la evolución en base a variabilidad genética ya presente en el acervo genético de una especie, el margen de evolución de una especie sería limitado. Más aún, cada carácter variable ya incorporado al acervo genético de una especie no puede ser entendido sino como una mutación en su origen.

Podemos resumir muy esquemáticamente la teoría de la evolución por selección natural de la siguiente manera: cierta mutación azarosa en la genética de cierto individuo resulta casualmente beneficiosa en relación a la adaptación de dicho individuo al medio, favoreciendo sus posibilidades de reproducción. El individuo favorecido comunicará el nuevo carácter a su descendencia. Dado que no todos los individuos de una generación llegan a reproducirse, el nuevo carácter introducido puede llegar eventualmente a formar parte de la genética de todos los individuos de la especie. Este mecanismo, capaz de explicar la evolución de una especie, puede de la misma manera explicar el origen de una nueva especie a partir de otra, dadas ciertas condiciones, como el aislamiento geográfico.

\section{2.- Aplicaciones alternativas de la teoría de selección natural}

La primera referencia que queremos hacer aquí es a cierta teoría que pretende dar cuenta del origen de la vida extendiendo el mecanismo de la selección natural a formas físico-químicas. La teoría supone que puede tener lugar una suerte de evolución por selección natural de moléculas que, por combinaciones fortuitas, llegan a tener un alto grado de estabilidad frente a otras. Dadas ciertas condiciones de un medio, una forma físico-química puede de hecho tener mayor estabilidad que otra: en el sol el átomo de helio es más estable que el de hidrógeno, tornándose el primero progresivamente más abundante que el segundo (Dawkins 1993, p. 24). Se puede suponer que a partir de una combinación fortuita debió aparecer en un momento del tiempo geológico una molécula que por su sola estructura química sea capaz de producir copias de sí misma. Este primer "replicador" (llamado así por Dawkins en su popularizada obra El gen egoísta) representa de manera remota el origen de la vida.

No es necesario suponer que este replicador sea capaz de producir activamente una copia de sí. Basta con suponer que por afinidades químicas, ciertas moléculas más 
pequeñas presentes en el medio del replicador se acoplen a él hasta que la estructura completa se torne inestable y se divida en dos copias del replicador original. Evidentemente, un replicador será capaz de multiplicarse indefinidamente hasta que eventualmente entre en competencia con otros replicadores por los recursos del medio y se torne posible una selección natural de aquellos replicadores más eficaces. Dawkins (1993) supone que el punto culminante de este proceso evolutivo del replicador originario es la formación del ADN, presente en todas las formas vitales actuales (p. 34). Otro hito en la evolución de las formas vitales se halla representado por la formación, también azarosa, pero evolutivamente fecunda, de "vehículos protectores". Estos "vehículos", evolucionarían eventualmente hasta la formación de la célula y finalmente hasta la formación del organismo. Dawkins (1993) les llamará “máquinas de supervivencia” (p. 32).

La tesis de la obra que estamos citando es que la unidad evolutiva básica es el gen. De aquí el interés del autor en poner los fenotipos en función de los requerimientos evolutivos de los genotipos. Esa es la razón por la cual el ser vivo individual es para Dawkins una mera máquina de supervivencia controlada por los genes. Más allá de la viabilidad de la propuesta de Dawkins, es interesante señalar que son teóricamente concebibles diversos procesos de selección natural que actúan a diversos niveles: físicoquímico, genético, ser vivo individual. El autor incluso hace referencia a una teoría de selección de grupos, mostrándose en desacuerdo con ella (Dawkins 1993, p. 19). Particularmente, considero que no es necesario pensar que estos diversos niveles en los cuales operaría la selección natural sean mutuamente excluyentes. Si bien es posible que cierto proceso evolutivo se dispare en un solo nivel, incluso en detrimento de los otros niveles (recuérdese el mencionado a pie de página caso del gen $t$ del ratón), una mutación genética que repercuta favorablemente en más de un nivel, óptimamente en todos los niveles, mostrará un potencial evolutivo mucho más consistente que la que actúe en un solo nivel. ${ }^{2}$ Aunque ciertamente, concediendo parcialmente la tesis de Dawkins, cualquier evolución posible debe satisfacer ineludiblemente los requerimientos evolutivos del nivel genético.

2Para ilustrar este punto podemos apelar a un estudio que menciona el mismo Dawkins. En el último capítulo de la obra citada se consideran distintas estrategias de relación de un individuo con el grupo: desde las más cooperativas a las más egoístas. El estudio muestra que la estrategia evolutivamente mejor adaptada es aquella que coopera con el grupo sin poner en riesgo la integridad individual. El juego experimental se llama "Dilema del prisionero", la estrategia ganadora "Donde las dan las toman" (Dawkins 1993, p. 285). Consiste en cooperar en el primer movimiento y luego imitar el movimiento del rival. 
Seguidamente queremos mostrar una muy interesante deriva de la teoría de la evolución por selección natural. Se trata de una explicación evolutiva que da cuenta de la correlación entre fenómenos mentales y cerebros. Ciertamente, si este órgano fue desarrollado por algunas formas vitales en el transcurso del curso evolutivo, es porque éste representa una ventaja evolutiva para las mismas. La característica del cerebro es una incomparable plasticidad epigenética en relación con cualquier otro órgano. Esto permite una adaptación del animal individual al medio mucho más eficaz en comparación con una situación en la que éste dependiera enteramente de la evolución de los genes de toda la especie. La enorme variabilidad epigenética del cerebro permite al animal ensayar diversas respuestas hasta encontrar la mejor adaptada. De otro modo, cada ensayo debería ser llevado a cabo por toda la especie, quedando toda ella a la espera de una fortuita mutación genética para poder ensayar una respuesta alternativa, como ocurre presumiblemente en los vegetales, carentes de cerebro. En el corto transcurso de la vida de un animal individual, tiene lugar un proceso evolutivo epigenético en su cerebro. Tomando en cuenta aportes relativamente recientes de la neurociencia, podemos ir un poco más allá y afirmar que dada la enorme variabilidad epigenética del cerebro, es posible que en el mismo compitan diferentes entramados neuronales hasta alcanzar un punto crítico en el cual uno se estabiliza, desplaza a los otros y logra exteriorizarse. Este darwinismo intracerebral se debe originariamente a Changeaux (2009, p. 208). Siguiendo al anterior, Edelman (1992) desarrolló una teoría técnicamente más detallada conocida como "teoría de la selección de grupos neurales" (cap. 9).

Otro reconocido aporte de Dawkins es su teoría relativa a una cierta unidad de evolución cultural, análoga al gen, llamada meme. Primeramente, el autor considera que el fenómeno de la cultura no es privativo del hombre. Pone como ejemplo al respecto ciertas melodías de cierta especie de pájaros que se transmiten por sola imitación y que son diferentes en distintas poblaciones, aun constituyendo la misma especie. Eventualmente, por errores de copia o combinación de melodías ya conocidas, surgen nuevas melodías que prosperan en la medida en que se muestran eficaces para la atracción de la pareja. Dadas estas características del fenómeno, no puede pensarse que dichas melodías estén genéticamente determinadas, sino que tienen una constitución cultural (Dawkins 1993, p. 256). No obstante, la especie en la cual el dinamismo cultural alcanza un grado notable es el hombre. El ejemplo paradigmático de creación cultural es el lenguaje, sin embargo, existen innumerables conjuntos simbólicos creados por la mente humana. Según el autor, es posible identificar en estos sistemas de símbolos ciertas unidades 
evolutivas que, replicándose por imitación, compiten por conquistar el margen de variabilidad epigenética disponible en los cerebros humanos. Simplificando la palabra griega mimesis, el autor quiso llamar a esta unidad de evolución cultural meme, en clara correspondencia con la unidad de evolución biológica, el genes (Dawkins 1993, p. 259).

Considero que el punto más interesante de esta propuesta de Dawkins es dar cuenta de la posibilidad del surgimiento del orden de la cultura, análogo al de la biología, ineludiblemente relacionado, pero autónomo respecto de aquel. Me explico: sin duda la aparición y evolución del fenómeno mental en ciertas especies biológicas tuvo que obedecer a los impulsos de la evolución biológica. Pero una vez establecido un nuevo orden de objetos que crean un sistema autónomo (el conjunto de la cultura formado por múltiples memes interrelacionados), éste tiene sus propias leyes con independencia del orden biológico: ha surgido un nuevo nivel de la naturaleza, en el cual es posible un proceso evolutivo autónomo. Tan "egoísta” como el gen, el meme no "busca" sino la multiplicación de sí mismo: "de la misma manera que hemos considerado conveniente imaginar a los genes como agentes activos, trabajando intencionadamente por su propia supervivencia, quizá sea conveniente imaginar a los memes de igual forma” (Dawkins 1993, p. 270). Entonces, en la medida en que es posible concebir los procesos evolutivos por selección natural de modo abstracto, es decir, formas que compiten unas con otras más allá del sustrato en que lo hagan, pudimos reconocer un orden cultural diferente del biológico, pero ambos inscriptos en la naturaleza como distintos niveles de la misma, con interrelación pero con autonomía. Puntualmente, considero valioso el aporte en la medida en que permite un estudio de las leyes de la conciencia (y de la cultura) evitando un reduccionismo biologicista.

\section{3.- Razón de la potencia explicativa de la teoría}

Como insinuamos en la introducción, la teoría de la evolución por selección natural se muestra en el campo científico ella misma como una forma bien adaptada, en la medida en que ha trascendido el campo estrictamente biológico para el cual fue originalmente concebida y desplazado otro tipo de recursos teóricos anteriormente vigentes. La razón fundamental de la enorme fecundidad de esta idea es que logra una explicación de la emergencia y evolución de nuevos órdenes dentro de la naturaleza a partir de algún orden dado sin apelar a instancias externas a la naturaleza. Vale proponer aquí el célebre ejemplo del predarwiniano Paley: si camino por el desierto y encuentro un reloj, 
es decir, un objeto diseñado para responder a un propósito (medir el tiempo), tengo que suponer necesariamente una mente consciente como causa de dicho diseño (Paley 1825, p. 1). De la misma manera, si encuentro en la naturaleza objetos con un diseño que parece responder a un propósito, y dado que ellos mismos no pudieron conscientemente darse ese diseño, tengo que suponer un agente externo a la naturaleza como causa de tal diseño (Paley 1825, p. 8). Es el argumento teleológico, al que apelaron los filósofos desde antiguo para explicar el orden de la naturaleza (Platón, Fedón 97c - 99c). Los teólogos medievales adoptaron dicho argumento como prueba de la existencia de Dios (Tomás de Aquino, Suma Teológica I q.2 a.3).

El carácter recesivo del argumento teleológico en el medio cultural de la mentalidad moderna está dado en la medida en que infringe un supuesto básico de una comprensión científica del mundo: todo fenómeno natural ha de tener una causa natural el llamado "principio del cierre causal del orden físico" (Lowe 2004, p. 27). El argumento teleológico viola este principio de un doble modo: primeramente supone un agente extranatural, que por ello mismo queda fuera del campo de lo cognoscible. En segundo lugar, termina ofreciendo una imagen del todo natural donde la cadena de las causas queda suturada entre un orden y otro por intervenciones ininteligibles. El mundo queda fragmentado por intervenciones sobrenaturales, perdiendo éste su unidad última. A todas luces, el argumento teleológico es, desde el punto de vista del paradigma científico moderno, lo contrario de una explicación. Una explicación científica no puede ser sino una concesión al naturalismo (Dupré 2006, p. 69-70). Apelar a una mente para explicar la naturaleza equivale precisamente a una renuncia a la búsqueda de una explicación. Una explicación científica debe explicar la mente por la naturaleza, y no al revés.

El mecanismo de selección natural es en el mencionado medio extremadamente seductor dado que es precisamente eso: un mecanismo. No hay necesidad alguna de postular un diseño previo, una finalidad preconcebida. Lo que desde el actual estadio evolutivo nos parece un progreso hacia un fin, no es sino la acumulación constante de formas que en cada estadio han sobrevivido a las presiones del medio en ese momento dado. La teoría de la selección natural sólo necesita un supuesto: el orden. A partir de un orden básico, la selección natural es capaz de dar cuenta de la aparición del diseño. Antes de Darwin, la diferencia entre orden y diseño no era visible, ya que todo en definitiva provenía de un agente sobrenatural (Dennett 1999, p. 96). Debe entenderse por orden la simple regularidad de la naturaleza. Se suponía diseño en aquellas formas que además de responder a regularidades aparentan perseguir un fin. Pues bien, Darwin logra satis- 
factoriamente reducir todo aparente diseño a orden. Todo diseño biológico, incluso cultural, podría ser explicado por un mecanismo ciego a partir del básico orden físicoquímico.

El carácter netamente naturalista de la teoría de la selección natural queda mejor ilustrado bajo la consideración de Dennett (1999) del proceso evolutivo como un simple algoritmo: "proceso formal que puede llegar a producir - de forma lógica- un resultado determinado siempre que se le haga funcionar o sea puesto en marcha" (p. 71). Un algoritmo es un proceso formal y puede ser llevado a cabo sobre cualquier sustrato y se ejecuta mecánicamente, sin necesidad de conciencia alguna, como un programa de computadora. Curiosamente, David Hume juega con la posibilidad de un proceso que hoy consideraríamos algorítmico para explicar el supuesto diseño:

“QQué sorpresa nos invadiría si lo que encontramos es un estúpido mecánico que imita a los otros y copia un arte, el cual, a través de una larga sucesión de edades, después de múltiples ensayos, errores, correcciones, deliberaciones y controversias, ha sido gradualmente mejorado? Muchos mundos pueden haber sido construidos chapuceramente, a través de una eternidad antes de que su sistema fuera destruido: mucho trabajo perdido, muchos ensayos infructuosos realizados, una lenta pero continuada mejoría conseguida durante infinitas edades de construcción del mundo" (citado por Dennett 1999, p. 38).

Ciertamente, la confección de un ser vivo bien adaptado al medio comportaría un conocimiento completo de las leyes de la naturaleza si se quiere evitar innumerables ensayos fallidos. Más aún, solo una mente divina podría acertar con el diseño perfecto sin la mediación de ensayos relativamente fallidos. Pero, si se le da tiempo a un "estúpido mecánico" para que ensaye virtualmente infinitas posibilidades, eventualmente por azar acertará con los caracteres adecuados que, por el hecho mismo de ser casualmente adecuados quedan incorporados al diseño. Es posible una comparación con el desarrollo del conocimiento: el científico valioso será aquel capaz de imaginar una hipótesis satisfactoria para explicar un fenómeno. Pero también un ciego ordenador que construya aleatoriamente hipótesis podría eventualmente encontrar una que salve los hechos. Pues bien, Darwin halló al "estúpido mecánico" con mucho tiempo para realizar sus ensayos, es decir, un algoritmo (o una combinación de ellos) capaz de sustituir la mente detrás del diseño. Se torna más visible aún cómo el algoritmo de la selección natural prescinde de toda mente diseñadora cuando consideramos que, para que el algoritmo funcione 
correctamente, necesita del (aparente) error: si todas las copias fueran exactas, si no existieran mutaciones, no habría evolución alguna.

En tiempos de Darwin eran habituales las explicaciones teleológicas de fenómenos naturales como argumento apologético. El razonamiento de Paley apuntaba no tanto a explicar la evolución de las especies como a demostrar la existencia de Dios (nótese el título de la obra citada). La teoría de la selección natural ha conseguido expulsar definitivamente al argumento teleológico del campo de la explicación científica. Sólo queda un lugar posible a la teleología: el campo del discurso metafísico. Sigue siendo teóricamente concebible la posibilidad de una mente ordenadora como causa final de la realidad toda. Pero dado que no hay medio alguno de probar tal posibilidad, dicho argumento es necesariamente metafísico y no puede confundirse ya con un argumento científico. Los fenómenos particulares de la naturaleza no tienen propósito alguno, pero la naturaleza toda aún puede tenerlo. Según Dennett, el propio Darwin expresó simpatía por esta idea: "Darwin tenía claro que la variación de la que depende el proceso de la evolución natural había de ser no planeada y no diseñada, pero ¿debía de tener el propio proceso un propósito?” (Dennett 1999, p. 99).

\section{Conclusión}

Aplicando la propia teoría de la selección natural al estatuto epistemológico de la misma teoría, nos propusimos en esta presentación mostrar cómo la evolución por selección natural es una explicación científica bien adaptaba al medio determinado por el paradigma científico actual. Primeramente dimos cuenta de los elementos constitutivos de la misma: reproducción de las especies biológicas alterable por mutaciones genéticas; presiones del medio que fuerzan una competencia de los individuos por alcanzar el éxito reproductivo; selección natural de los caracteres que favorecen la adaptación; evolución de las especies o surgimiento de otras nuevas. Posteriormente vimos cómo, por su carácter formal, el proceso de evolución por selección natural puede aplicarse a otros sustratos distintos del biológico, pudiendo brindar explicaciones satisfactorias, o al menos promisorias líneas de investigación, en el campo de los fenómenos mentales y culturales. Finalmente, considero que pudimos poner en evidencia la razón de la fecundidad de la teoría: el proceso de evolución por selección natural es un simple algoritmo (o conjunto de ellos) que torna superfluas las arriesgadas explicaciones de carácter teleológico. La comprensión científica del fenómeno del (aparente) diseño permaneció 
durante siglos bloqueada por el inmoderado recurso a una mente ordenadora trascendente. La súbita aparición de la teoría desplazó definitivamente tales intentos.

\section{Bibliografía}

Changeaux, J. P. (2009). The Physiology of Truth. Harvard, EEUU: Harvard University Press.

Darwin, C. (1921). El origen de las especies. Trad. A. Zulueta. Madrid, España: EspasaCalpe.

Dawkins, R. (1993). El gen egoísta, Barcelona, España: Salvat.

Dennett, D. (1999). La peligrosa idea de Darwin, Barcelona, España: Galaxia Gutenberg.

Dupré, J. (2006). El legado de Darwin. Buenos Aires, Argentina: Katz.

Edelman, G. M. (1992). Bright Air, Brilliant Fire. New York, EEUU: BasicBooks

Lamarck, J. (1986). Filosofía Zoológica. Barcelona, España: Alta Fulla.

Lowe, E. J. (2004). An Introduction to the Philosophy of the Mind, Cambridge, UK: Cambridge University Press.

Paley, W. (1825). Teología natural. Trad. Villanueva. Londres, UK: Ackermann.

Rostand, J. (1994). Introducción a la historia de la biología. Madrid, España: PlanetaAgostini. 